九州大学学術情報リポジトリ

Kyushu University Institutional Repository

\title{
Effects of Nitrogen Deficiency on Dry Matter and Grain Productions of Six Rice (Oryza sativa L. ) Cultivars
}

\section{Kumagai, Etsushi}

NARO Tohoku Agricultural Research Center

Araki, Takuya

Faculty of Agriculture, Ehime University

Kubota, Fumitake

Emeritus Professor, Kyushu University

Ueno, Osamu

Emeritus Professor, Kyushu University

https://doi.org/10.5109/22045

出版情報：九州大学大学院農学研究院紀要. 57 (1)，pp.35-39，2012-02. Faculty of Agriculture， Kyushu University

バージョン :

権利関係 : 


\title{
Effects of Nitrogen Deficiency on Dry Matter and Grain Productions of Six Rice (Oryza sativa L.) Cultivars
}

\author{
Etsushi KUMAGAI ${ }^{1 *}$, Takuya ARAKI ${ }^{2}$, Fumitake KUBOTA ${ }^{3}$ \\ and Osamu UENO
}

\author{
Laboratory of Plant Production Physiology, Division of Agricultural Bioresource Sciences, \\ Department of Bioresource Sciences, Faculty of Agriculture, \\ Kyushu University, Hakozaki, Fukuoka 812-8581, Japan \\ (Received October 14, 2011 and accepted November 9, 2011)
}

\begin{abstract}
Effects of limited nitrogen (N) supply on dry matter and grain productions were investigated in the pot-grown six rice cultivars, Kasalath (a traditional indica), IR36 (an improved indica), Shirobeniya (a conventional japonica), Nipponbare (an improved japonica), BSI429 (an improved tropical japonica, a new plant type line) and Akenohoshi (an improved japonica-indica cross). At maturity, $\mathrm{N}$ limitation caused significant decreases in aboveground dry weight (DW), DW increased during heading to maturity $(\Delta \mathrm{DW})$, grain weight, panicle number per plant, fertility \% and sink size in the six cultivars, and there were significant "cultivar $\times$ N" interactions; the magnitudes of these decreases caused by limited N supply were smallest in Akenohoshi. There were significant positive correlations between grain weight and aboveground DW at maturity under both standard-N (SN) and low-N (LN) conditions, whereas there was a significant positive correlation between grain weight and $\triangle \mathrm{DW}$ under the LN condition but not under the SN condition. Grain weight was more closely correlated with sink size under both $\mathrm{N}$ conditions. Among the cultivars examined, Akenohoshi showed the highest $\Delta \mathrm{DW}$, fertility \% and sink size under the LN condition, leading the highest grain weight. It is suggested that Akenohoshi is a breeding material useful for the improvement of adaptability to LN environment.
\end{abstract}

Key words: Grain yield, Nitrogen deficiency, Rice, Yield components

\section{INTRODUCTION}

Over the last 50 years, rice production in Asia has kept pace with the increasing population. The rice production system consisting of high yielding cultivars, high input of fertilizers and agrochemicals, and irrigation contributed to great yield increases in both developed and developing countries during the past decades (Evans, 1993). However, adverse effects of high input agriculture have been recognized. Nitrate and agrochemicals discharged from agriculture cause both surface and underground water pollution (Jarvis, 1996). Nitrogen (N) fertilizer is one of the most important inputs in the production package. Fertilizers account for almost half of the energy used in world agriculture, and the manufacture of $\mathrm{N}$ fertilizer is about 10 times more energy-intensive than that of other fertilizers such as phosphate (P) and potassium (K) (Evans, 1993). Recently, the soaring world oil prices also raise a problem of $\mathrm{N}$ fertilizer cost. In rice, reduced rate of $\mathrm{N}$ fertilizer application can diminish the occurrence of blast disease and several insect pests such as planthoppers and can reduce the use of the fungicides and insecticides. In addition, reduced application of $\mathrm{N}$ fertilizer can contribute to reducing dinitrogen monoxide $\left(\mathrm{N}_{2} \mathrm{O}\right)$ emission from agricultural soils resulting in global warming.

\footnotetext{
NARO Tohoku Agricultural Research Center, Akahira, Shimokuriyagawa, Morioka 020-0198, Japan

Faculty of Agriculture, Ehime University, Tarumi, Matsuyama, Ehime 790-8566, Japan

Emeritus Professor, Kyushu University

* Corresponding author (E-mail: ekumagai@affrc.go.jp)
}

The main goals of the rice production system are the optimization of grain yield, the reduction of production cost and the minimization of the pollution risk for the environment. At present, genetic improvements of crops that will be used in low input sustainable agricultural system are required, but most of the previous genetic improvements were conducted presupposing cultivation under high input conditions. In wheat, Austin et al. (1980) found that high yielding cultivars performed better than traditional ones in both fertile and less fertile soils. Ortiz-Monasterio et al. (1997) also found that newly released wheat cultivars attained higher grain yield than old cultivars even without application of $\mathrm{N}$ fertilizer. Newly released maize hybrids also outperformed traditional ones even at reduced $\mathrm{N}$ application rates (Ding et $a l .$, 2005). In spite of these studies, there are still some opinions that high yielding cereal cultivars may not be used in low input cropping systems. With respect to this, Evans (1993) stated that "there are more strong opinions than strong data". Actually, there are few comparative studies on the production of rice under LN input conditions (Hasegawa, 2003). In order to elucidate the adaptability to LN environment in rice cultivars, we investigated some characteristics of dry matter and grain productions in several traditional and newly improved rice cultivars grown under the SN and LN conditions.

\section{MATERIALS AND METHODS}

\section{Plant materials and $\mathbf{N}$ treatment}

Six rice cultivars, Kasalath (a traditional indica), IR36 (an improved indica), Shirobeniya (a traditional 
japonica), Nipponbare (an improved japonica), BSI429 (an improved tropical japonica, a new plant type (NPT) line) and Akenohoshi (an improved japonica-indica cross), were used in this experiment. Imbibed seeds of these cultivars were sown in nursery boxes in a glass house of the Hakozaki Campus of Kyushu University at the beginning of June 2006. At three weeks after sowing, the seedlings (a seeding per pot) were transplanted into 8-L pots filled with sandy loam. The total $\mathrm{N}$ of the soil was $1.35 \mathrm{mg} \mathrm{g}^{-1}$. They were divided into the $\mathrm{SN}$ (Control) and LN (50\% of SN) groups. In the SN group, $\mathrm{N}$ fertilizer was applied at a rate of $0.96 \mathrm{~g} \mathrm{pot}^{-1}$ at transplanting, followed by $0.64 \mathrm{~g}^{-1}$ pot $^{-1}$ at panicle initiation. For the LN group, $0.48 \mathrm{~g} \mathrm{pot}^{-1}$ of $\mathrm{N}$ was applied at transplanting, followed by $0.32 \mathrm{~g}^{\mathrm{g}^{-1}}$ at panicle initiation. Ammonium sulfate was used as $\mathrm{N}$ fertilizer. In both groups, $1.6 \mathrm{~g} \mathrm{pot}^{-1}$ of $\mathrm{P}$ and $1.6 \mathrm{~g} \mathrm{pot}^{-1}$ of $\mathrm{K}$ were also applied in form of calcium superphosphate and potassium chloride, respectively. Pots were arranged without mutual-shading in the glass house under natural sunlight. Water was supplied sufficiently throughout. Weeds were removed manually when necessary.

\section{Measurements}

The dates of heading and maturity of each pot were recorded. The heading date was defined as the date when $50 \%$ of the panicles had fully emerged. The maturity date was determined as the date when $80 \%$ of spikelets became yellow. The aboveground parts of three plants per cultivar were sampled at heading for each $\mathrm{N}$ condi- tion, and leaf blades were detached from the rest of the plant parts. The leaf area (LA) of samples was measured with an automatic area meter (AAM-8, Hayashi Denko Co. Ltd., Tokyo, Japan). Their DWs were determined after drying in an oven at $80^{\circ} \mathrm{C}$ for 3 days. At maturity, three plants per cultivar were harvested for each $\mathrm{N}$ condition and air dried, and the aboveground DW of the plants was measured. And then, the panicle number per plant and spikelet number per panicle were counted. After threshing, ripened grains were selected by soaking unhulled grains in a salt solution of 1.06 specific gravity, and the percentage of ripened grains (fertility \%) was estimated. After air-drying in the grain moisture range of $13-14 \%$, grain weight per plant and 1000-grains weight were estimated. Sink size is the product of the spikelet number per plant multiplied by an average weight of grain with moisture of $13-14 \%$.

\section{Statistical analysis}

Data were statistically analyzed by a two-way analysis of variance (ANOVA) using a Sigmastat software (Sigmastat 3.1, Systat Software, Inc., Richmond, USA). Then, the significance of mean values was analyzed using Fisher's LSD test $(P<0.05)$.

\section{RESULTS AND DISCUSSION}

Table 1 shows days from transplanting to heading, LA at the heading stage, aboveground DW at the heading and mature stages, and $\Delta \mathrm{DW}$ in the six cultivars grown

Table 1. Days from transplanting to heading, leaf area (LA) at the heading stage, aboveground dry weight (DW) at the heading and mature stages, and DW increased from heading to mature stages $(\Delta \mathrm{DW})$ for the six cultivars grown under two nitrogen $(\mathrm{N})$ levels. SN, standard-N; LN, low-N. Values are given as the mean $\pm \mathrm{SE}(\mathrm{n}=3)$. Values followed by the same letters in the column had no significant difference as determined by Fisher's LSD test at $5 \%$ level. Values in parentheses represent the ratio compared to SN. Results of two-way ANOVA: ***, $P<0.001 ; * *, P<0.01 ; *, P<0.05$

\begin{tabular}{|c|c|c|c|c|c|c|c|c|c|c|c|}
\hline \multirow{3}{*}{$\begin{array}{l}\text { Cultivar } \\
\text { Kasalath }\end{array}$} & \multirow[t]{2}{*}{ Treatment } & \multirow{2}{*}{\multicolumn{2}{|c|}{$\begin{array}{l}\text { Days to } \\
\text { heading }\end{array}$}} & \multirow{2}{*}{\multicolumn{2}{|c|}{$\begin{array}{l}\text { LA at heading } \\
\left(\mathrm{m}^{2} \text { plant }^{-1}\right)\end{array}$}} & \multicolumn{4}{|c|}{$\begin{array}{l}\text { Aboveground DW } \\
\left(\mathrm{g} \text { plant }{ }^{-1}\right)\end{array}$} & \multirow{2}{*}{\multicolumn{2}{|c|}{$\begin{array}{c}\Delta \mathrm{DW} \\
\left(\mathrm{g}^{\mathrm{p}} \text { plant }^{-1}\right)\end{array}$}} \\
\hline & & & & & & \multicolumn{2}{|c|}{ Heading } & \multicolumn{2}{|c|}{ Maturity } & & \\
\hline & $\mathrm{SN}$ & $66 \pm 0.3 \mathrm{c}$ & & $1.13 \pm 0.02 \mathrm{a}$ & & $152 \pm 5.7 \mathrm{a}$ & & $191 \pm 5.4 \mathrm{a}$ & & $39 \pm 4.4 \mathrm{cde}$ & \\
\hline & $\mathrm{LN}$ & $60 \pm 0.3 \mathrm{ef}$ & (91) & $0.56 \pm 0.01 \mathrm{~d}$ & (50) & $91 \pm 1.5 \mathrm{~cd}$ & $(60)$ & $108 \pm 3.6 \mathrm{~d}$ & (57) & $17 \pm 3.0 \mathrm{~g}$ & (43) \\
\hline \multirow[t]{2}{*}{ IR36 } & $\mathrm{SN}$ & $65 \pm 0.0 \mathrm{~d}$ & & $0.74 \pm 0.04 \mathrm{~b}$ & & $95 \pm 3.0 \mathrm{bc}$ & & $145 \pm 9.1 b c$ & & $50 \pm 7.4 \mathrm{bc}$ & \\
\hline & $\mathrm{LN}$ & $62 \pm 0.3 \mathrm{e}$ & (95) & $0.33 \pm 0.02 \mathrm{f}$ & (45) & $63 \pm 4.1 \mathrm{e}$ & $(66)$ & $83 \pm 3.3 \mathrm{f}$ & (57) & $20 \pm 2.7 \mathrm{fg}$ & $(40)$ \\
\hline \multirow[t]{2}{*}{ Shirobeniya } & $\mathrm{SN}$ & $65 \pm 0.3 \mathrm{~cd}$ & & $0.61 \pm 0.02 \mathrm{~d}$ & & $80 \pm 1.2 \mathrm{~d}$ & & $141 \pm 5.1 b c$ & & $61 \pm 4.2 \mathrm{ab}$ & \\
\hline & $\mathrm{LN}$ & $59 \pm 0.3 \mathrm{~g}$ & (91) & $0.30 \pm 0.02 \mathrm{f}$ & (49) & $55 \pm 0.4 \mathrm{f}$ & (69) & $76 \pm 3.4 \mathrm{fg}$ & $(54)$ & $21 \pm 2.8 \mathrm{defg}$ & (34) \\
\hline \multirow[t]{2}{*}{ Nipponbare } & SN & $55 \pm 0.3 \mathrm{i}$ & & $0.62 \pm 0.02 \mathrm{~cd}$ & & $68 \pm 1.2 \mathrm{~d}$ & & $117 \pm 3.5$ de & & $48 \pm 2.9 \mathrm{bc}$ & \\
\hline & $\mathrm{LN}$ & $53 \pm 0.3 \mathrm{j}$ & (97) & $0.32 \pm 0.01 \mathrm{f}$ & (52) & $45 \pm 0.3 \mathrm{f}$ & (66) & $67 \pm 2.8 \mathrm{~g}$ & (58) & $22 \pm 2.3 \mathrm{defg}$ & (46) \\
\hline \multirow[t]{2}{*}{ BSI429 } & $\mathrm{SN}$ & $77 \pm 0.3 \mathrm{a}$ & & $0.58 \pm 0.01 \mathrm{~d}$ & & $96 \pm 3.2 \mathrm{~b}$ & & $135 \pm 1.5 \mathrm{c}$ & & $39 \pm 4.7 \mathrm{~cd}$ & \\
\hline & $\mathrm{LN}$ & $73 \pm 0.5 b$ & (95) & $0.31 \pm 0.01 \mathrm{f}$ & (53) & $65 \pm 1.0 \mathrm{de}$ & (68) & $85 \pm 2.2 f$ & (63) & $20 \pm 1.8$ efg & (51) \\
\hline \multirow[t]{2}{*}{ Akenohoshi } & $\mathrm{SN}$ & $60 \pm 0.0 \mathrm{fg}$ & & $0.64 \pm 0.02 \mathrm{~cd}$ & & $83 \pm 2.9 \mathrm{~cd}$ & & $153 \pm 1.5 b$ & & $70 \pm 1.2 \mathrm{a}$ & \\
\hline & $\mathrm{LN}$ & $57 \pm 0.0 \mathrm{~h}$ & (95) & $0.38 \pm 0.01 \mathrm{e}$ & (59) & $65 \pm 1.7 \mathrm{e}$ & (78) & $102 \pm 1.5 \mathrm{e}$ & (67) & $38 \pm 1.3 \mathrm{cdef}$ & (55) \\
\hline \multicolumn{12}{|c|}{ Results of two-way ANOVA } \\
\hline Cultivar (C) & & $* * *$ & & $* * *$ & & $* * *$ & & $* * *$ & & $* * *$ & \\
\hline Nitrogen $(\mathrm{N})$ & & $* * *$ & & $* * *$ & & $* * *$ & & $* * *$ & & $* * *$ & \\
\hline $\mathrm{C} \times \mathrm{N}$ & & $* * *$ & & $* *$ & & $* * *$ & & $* *$ & & * & \\
\hline
\end{tabular}


under the SN and LN conditions. Days from transplanting to heading ranged from 53 to 77 days. The days were shortest in Nipponbare, followed by Akenohoshi, Shirobeniya, IR36, Kasalath and BSI429. Moreover, days to heading were longer in the SN plants than in the LN plants for all the cultivars. LA and aboveground DW at the heading stage of the LN plants were decreased to $45-59 \%$ and $60-78 \%$ of the SN plants in all cultivars, respectively. The magnitude of decreases differed among the cultivars: Akenohoshi showed the smallest decreases of LA and aboveground DW at the heading stage under the $\mathrm{LN}$ condition (59\% and 78\%, respectively). However, there were no relationships between LA and aboveground DW, and days to heading under the two N conditions (data not shown), indicating that the dry matter production before heading was not associated with the duration of vegetative stage.

At maturity, $\mathrm{N}$ limitation significantly decreased aboveground DW (54-67\%), and there was a significant "cultivar $\times \mathrm{N}$ " interaction; the magnitude of the decrease in aboveground DW caused by $\mathrm{N}$ limitation was smallest in Akenohoshi (67\%) and largest in Shirobeniya (54\%). In addition, $\Delta \mathrm{DW}$ was significantly affected by $\mathrm{N}$ limitation, and there was a significant "cultivar $\times$ N" interaction; the decrease in $\Delta \mathrm{DW}$ was smallest in Akenohoshi (55\%) and largest in Shirobeniya (34\%). There was no difference in the duration of ripening regardless of the differences in cultivar and $\mathrm{N}$ application (data not shown). As shown in Table 2, $\mathrm{N}$ limitation significantly decreased grain weight, and there was a significant "cultivar $\times \mathrm{N}$ " interaction. The decrease in grain weight was smallest in Akenohoshi (62\%) and largest in Shirobeniya (47\%).
Furthermore, Akenohoshi has the highest grain weight under the LN condition. Grain weight was significantly correlated with LA and aboveground DW at the heading
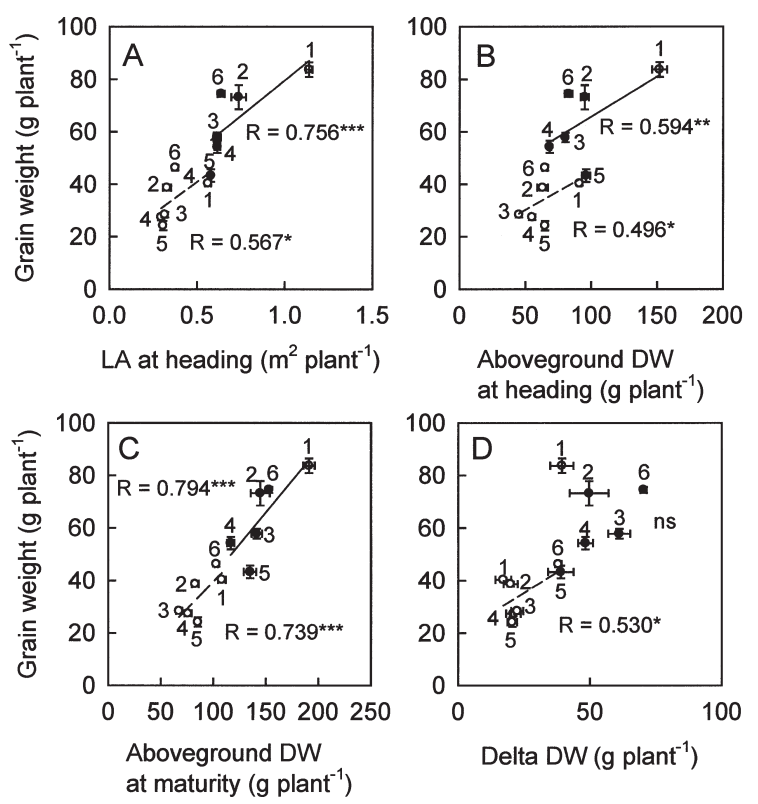

Fig. 1. Relationships between grain weight and leaf area (LA) at the heading stage (A), aboveground dry weight (DW) at the heading stage (B), aboveground DW at the mature stage $(C)$, and increased DW from heading to mature stages $(\triangle D W)(D)$ in the six rice cultivars grown under the standard-N (SN) and low-N (LN) conditions. Closed circle; SN, Opened circle; LN. ***, $P<0.001$; **, $P<0.01$; * $P<0.05 ;$ ns, not significant. 1, Kasatah; 2, IR36; 3, Shirobeniya; 4, Nipponbare; 5, BSI429; 6, Akenohoshi.

Table 2. Grain weight, panicle number per plant, spikelet number per panicle, fertility \%, 1000-grains weight, sink size for the six cultivars grown under two nitrogen $(\mathrm{N})$ levels. SN, standard-N; LN, low-N. Values are given as the mean $\pm \mathrm{SE}$ ( $\mathrm{n}=3$ ). Values followed by the same letters in the column had no significant difference as determined by Fisher's LSD test at $5 \%$ level. Values in parentheses represent the ratio compared to SN. Results of two-way ANOVA: $* * *, P<0.001 ; * *, P<0.01 ; *, P<0.05$; ns, not significant

\begin{tabular}{|c|c|c|c|c|c|c|c|c|c|c|c|c|}
\hline \multirow{2}{*}{$\begin{array}{r}\text { Cultivar } \\
\text { Kasalath }\end{array}$} & Treatment & \multicolumn{2}{|c|}{$\begin{array}{l}\text { Grain weight } \\
\left(\mathrm{g}_{\text {plant }}^{-1}\right)\end{array}$} & \multicolumn{2}{|c|}{$\begin{array}{c}\text { Panicle number } \\
\text { per plant }\end{array}$} & \multicolumn{2}{|c|}{$\begin{array}{l}\text { Spikelet number } \\
\text { per panicle }\end{array}$} & $\begin{array}{c}\text { Fertility } \\
\%\end{array}$ & \multicolumn{2}{|c|}{$\begin{array}{l}\text { 1000-grains } \\
\text { weight (g) }\end{array}$} & \multicolumn{2}{|c|}{$\begin{array}{l}\text { Sink size } \\
\left(\mathrm{g} \mathrm{plant}^{-1}\right)\end{array}$} \\
\hline & SN & $84 \pm 2.8 \mathrm{a}$ & & $41 \pm 1.3 \mathrm{a}$ & & $135 \pm 3.3 \mathrm{a}$ & & $81.2 \pm 0.6 \mathrm{a}$ & $18.3 \pm 0.3 \mathrm{de}$ & & $103 \pm 2.3 \mathrm{a}$ & \\
\hline & $\mathrm{LN}$ & $40 \pm 0.7 \mathrm{e}$ & $(48)$ & $26 \pm 0.3 \mathrm{~d}$ & (63) & $132 \pm 1.3 \mathrm{a}$ & (98) & $66.7 \pm 0.6 \mathrm{ef}(82)$ & $17.9 \pm 0.1 \mathrm{e}$ & $(98)$ & $60 \pm 0.5 f$ & (58) \\
\hline \multirow[t]{2}{*}{ IR36 } & $\mathrm{SN}$ & $73 \pm 4.6 \mathrm{bc}$ & & $38 \pm 1.2 \mathrm{~b}$ & & $124 \pm 6.7 \mathrm{abc}$ & & $78.8 \pm 3.0 \mathrm{ab}$ & $19.7 \pm 0.3 \mathrm{~d}$ & & $93 \pm 2.5 b$ & \\
\hline & $\mathrm{LN}$ & $38 \pm 1.0 f$ & $(52)$ & $23 \pm 1.4 \mathrm{e}$ & $(60)$ & $117 \pm 2.5 b c$ & $(95)$ & $73.8 \pm 2.2 \mathrm{~cd}(94)$ & $19.3 \pm 0.2 \mathrm{~d}$ & $(98)$ & $53 \pm 2.2 \mathrm{~g}$ & (57) \\
\hline \multirow[t]{2}{*}{ Shirobeniya } & SN & $57 \pm 1.8 \mathrm{bc}$ & & $41 \pm 0.6 \mathrm{ab}$ & & $84 \pm 2.7 \mathrm{~d}$ & & $70.4 \pm 1.5 \mathrm{de}$ & $23.6 \pm 0.4 b$ & & $82 \pm 2.3 c$ & \\
\hline & $\mathrm{LN}$ & $27 \pm 1.1 \mathrm{fg}$ & $(47)$ & $24 \pm 0.3 \mathrm{de}$ & $(59)$ & $84 \pm 2.3 \mathrm{~d}$ & $(94)$ & $63.9 \pm 0.5 \mathrm{fg} \quad(91)$ & $23.3 \pm 0.4 b$ & (99) & $46 \pm 1.2 \mathrm{~h}$ & (56) \\
\hline \multirow[t]{2}{*}{ Nipponbare } & $\mathrm{SN}$ & $54 \pm 2.4 \mathrm{de}$ & & $40 \pm 0.0 \mathrm{ab}$ & & $79 \pm 2.1 \mathrm{~d}$ & & $79.4 \pm 1.6 \mathrm{ab}$ & $21.5 \pm 0.3 \mathrm{c}$ & & $68 \pm 1.6 \mathrm{de}$ & \\
\hline & $\mathrm{LN}$ & $28 \pm 1.0 \mathrm{~g}$ & $(52)$ & $22 \pm 0.7 \mathrm{ef}$ & $(55)$ & $78 \pm 2.1 \mathrm{~d}$ & $(99)$ & $75.8 \pm 1.7 \mathrm{bc}(95)$ & $22.1 \pm 0.6 c$ & (103) & $37 \pm 0.7 \mathrm{i}$ & $(54)$ \\
\hline \multirow[t]{2}{*}{ BSI429 } & SN & $43 \pm 2.4 \mathrm{de}$ & & $20 \pm 1.5 \mathrm{f}$ & & $115 \pm 10.1 \mathrm{c}$ & & $60.6 \pm 0.7 \mathrm{~g}$ & $31.8 \pm 0.5 \mathrm{a}$ & & $71 \pm 2.7 \mathrm{~d}$ & \\
\hline & $\mathrm{LN}$ & $24 \pm 1.8 \mathrm{f}$ & $(56)$ & $13 \pm 0.3 \mathrm{~h}$ & $(65)$ & $110 \pm 4.5 \mathrm{c}$ & $(96)$ & $52.9 \pm 3.1 \mathrm{~h} \quad(87)$ & $31.2 \pm 0.6 \mathrm{a}$ & $(98)$ & $45 \pm 1.8 \mathrm{~h}$ & $(63)$ \\
\hline \multirow[t]{2}{*}{ Akenohoshi } & $\mathrm{SN}$ & $74 \pm 1.1 \mathrm{~b}$ & & $30 \pm 2.4 \mathrm{c}$ & & $130 \pm 6.9 \mathrm{ab}$ & & $82.5 \pm 1.1 \mathrm{a}$ & $23.7 \pm 0.1 b$ & & $90 \pm 1.9 \mathrm{~b}$ & \\
\hline & $\mathrm{LN}$ & $46 \pm 1.0 \mathrm{~d}$ & $(62)$ & $21 \pm 0.0 f$ & $(70)$ & $130 \pm 5.7 \mathrm{ab}$ & $(100)$ & $81.9 \pm 0.7 \mathrm{a} \quad(99)$ & $23.6 \pm 0.2 b$ & $(100)$ & $65 \pm 2.2 \mathrm{e}$ & $(72)$ \\
\hline \multicolumn{13}{|c|}{ Results of two-way ANOVA } \\
\hline \multicolumn{2}{|l|}{ Cultivar (C) } & $* * *$ & & $* * *$ & & $* * *$ & & $* * *$ & $* * *$ & & $* * *$ & \\
\hline \multicolumn{2}{|l|}{ Nitrogen $(\mathrm{N})$} & $* * *$ & & $* * *$ & & ns & & $* * *$ & ns & & $* * *$ & \\
\hline \multicolumn{2}{|l|}{$\mathrm{C} \times \mathrm{N}$} & $* * *$ & & $* * *$ & & $\mathrm{~ns}$ & & $*$ & $\mathrm{~ns}$ & & $* *$ & \\
\hline
\end{tabular}


stage under the two $\mathrm{N}$ conditions (Fig. 1-A and $-\mathrm{B}$ ), which indicates that at least dry matter production and LA expansion before heading would be contributors for the increase in grain weight of rice cultivars regardless of $\mathrm{N}$ levels. There were significant correlations between grain weight and aboveground DW at maturity under both SN and LN conditions (Fig. 1-C), whereas there was a significant correlation between grain weight and $\triangle \mathrm{DW}$ under the LN condition but not under the SN condition (Fig. 1-D). Among the six cultivars examined, Akenohoshi (No. 6) produced the highest dry matter during ripening under the $\mathrm{LN}$ condition, leading the highest grain weight.

Grain yield of rice is the final product of a combination of different yield components, such as panicle number per plant, spikelet number per panicle, fertility $\%$ and 1000-grains weight (Yoshida, 1981). In transplanted rice plants, spikelet number per plant is usually the most variable yield component, accounting for about $74 \%$ of the variation of yield. Both fertility \% and 1000 -grains weight account for $26 \%$ of the yield variation (Yoshida and Parao, 1976). This relative importance of each component varies with the cultural system. As shown in Table 2, limited $\mathrm{N}$ supply significantly decreased panicle number per plant, fertility \% and sink size, and there were significant "cultivar $\times \mathrm{N}$ " interactions; the magnitude of these decreases was smallest in Akenohoshi among the cultivars examined. On the other hand, the effects of limited N supply on spikelet number per panicle and 1000-grains weight were not significant. Grain weight was significantly correlated with panicle number per plant, spikelet number per panicle, fertility \% and sink size under both the SN and LN conditions (Fig. 2-A, -B,
$-\mathrm{C}$ and $-\mathrm{E}$ ). However, there was no correlation between grain weight and 1000-grains weight under each N condition (Fig. 2-D). Grain weight was more closely correlated with sink size under both $\mathrm{N}$ conditions, and this result agrees with those from many previous reports on rice (e.g., Takeda et al., 1984). Among the cultivars examined, Akenohoshi (No. 6) showed the highest fertility $\%$ and sink size, leading the highest grain weight under the LN condition (Table 2). As mentioned above, sink size is the product of the spikelet number per plant multiplied by weight of a grain. The size of rice grain is physically restricted by the size of the hull, and its weight is very stable under most environmental conditions (Yoshida, 1981). It has been reported that $\mathrm{N}$ uptake before heading is a critical factor in spikelet production (Hasegawa et al., 1994). It was previously observed that Akenohoshi has higher $\mathrm{N}$ uptake capacity than Nipponbare at the late-vegetative stage (Kumagai, 2007). Therefore, this cultivar may efficiently utilize N absorbed from soil for spikelet production under the LN condition. Fertility \% is mainly affected by the amount of carbohydrates available for grain filling (Kobata et al., 2000). The contribution of carbohydrates assimilated after heading to grain carbohydrates ranges from $60 \%$ to 100\% under most environmental conditions (Yoshida, 1981). Nagata et al. (2001) studied the effects of dry matter produced after heading and carbohydrates stored in stems before heading on grain filling and reported that the former had a stronger effect on fertility \% than the latter. Therefore, Akenohoshi could produce the highest dry matter after heading, leading the highest fertility \% under the LN condition.

Among leaves of rice plant, flag leaves are the primary
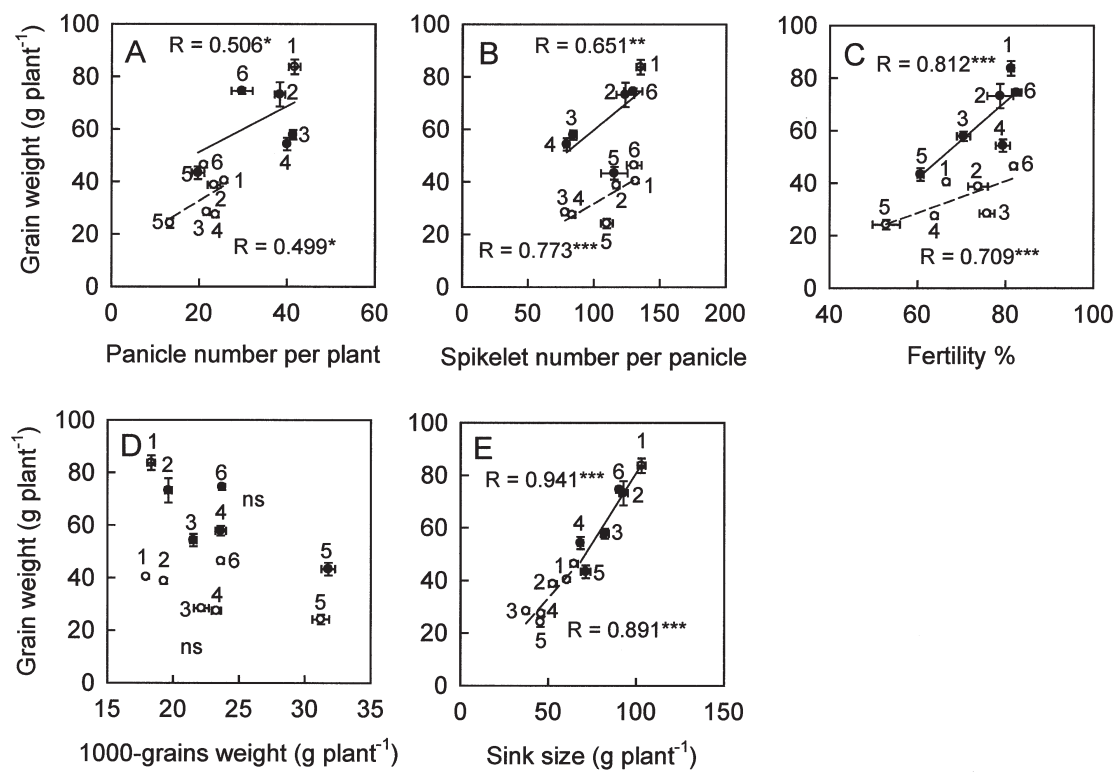

Fig. 2. Relationships between grain weight and panicle number per plant (A), spikelet number per panicle (B), fertility \% (C), 1000-grains weight (D) and sink size (E) in the six rice cultivars grown under the standard-N (SN) and low-N (LN) conditions. Closed circle; SN, Opened circle; LN. ***, $P<0.001$; **, $P<0.01 ; *, P<0.05$; ns, not significant. 1, Kasatah; 2, IR36; 3, Shirobeniya; 4, Nipponbare; 5, BSI429; 6, Akenohoshi. 
contributor to the accumulation of dry matter in grains (Murata and Matsushima, 1975; Black et al., 1995). Previously, we investigated the difference in flag leaf photosynthesis during ripening stage of rice cultivars grown under the LN condition and showed that a prolonged high photosynthetic rate was observed during the ripening stage in the flag leaves of Akenohoshi grown under the LN condition (Kumagai et al., 2009). Therefore, high $\Delta \mathrm{DW}$ in this cultivar under the LN condition could be explained by high photosynthetic productivity in the flag leaves after heading.

In conclusion, Akenohoshi significantly surpassed the other cultivars with respect to grain weight, $\Delta \mathrm{DW}$, fertility \% and sink size under the LN condition. Hasegawa (2003) observed high-yielding temperate rice cultivars bred in Japan outyielded traditional ones not only at high $\mathrm{N}$ application but at a reduced $\mathrm{N}$ application, which was supported with our data. These findings are opposite to the suggestion by Evans (1993) that high yielding cereal cultivars would perform well only in the presence of sufficient amounts of N fertilizers. Since there is an increasing requirement to minimize the $\mathrm{N}$ application from environmental problems, it is suggested that Akenohoshi is a breeding material useful for improvement of the adaptability to LN environment.

\section{REFERENCES}

Austin, R. B., J. Bingham, R. D. Blackwell, L. T. Evans, M. A. Ford, C. L. Morgan and M. Taylor 1980 Genetic improvements in winter wheat yields since 1900 and associated physiological changes. J. Agric. Sci., 94: 675-689

Black, C. C., Z. Tu, Z. A. Counce, P. Yao, and M. N. Angelov 1995 An integration of photosynthesis traits and mechanisms that can increase crop photosynthesis and grain production. Photosynth. Res., 46: 169-175

Ding, L., K. Wang, G. Jiang, D. Biswas, H. Xu, L. Li, and Y. Li 2005 Effects of nitrogen deficiency on photosynthetic traits of maize hybrids released in different years. Ann. Bot., 96: 625-630

Evans, L. T. 1993 Crop Evolution, Adaptation and Yield.
Cambridge University Press. Cambridge (England), pp. 317365

Hasegawa, H. 2003 High-yielding rice cultivars perform best even at reduced nitrogen fertilizer rate. Crop Sci., 43: 921-926

Hasegawa, T., Y. Kuroda, N. G. Seligman, and T. Horie. 1994 Response of spikelet number to plant nitrogen concentration and dry weight in paddy rice. Agron. J., 86: 673-676

Jarvis, S. C. 1996 Future trends in nitrogen research. Plant Soil, 181: $47-56$

Kobata, T., M. Sugawara and S. Takatu. 2000 Shading during early grain filling period does not affect potential grain dry matter increase in rice. Agron. J., 92: 411-417

Kumagai, E. 2007 Studies on the responses of dry matter production and leaf photosynthesis to nitrogen, especially nitrogen deficiency in lowland rice (Oryza sativa L.) cultivars. Master's Thesis, Graduate School of Bioresource and Bioenvironmental Sciences, Kyushu University, Fukuoka, Japan

Kumagai, E., T. Araki and F. Kubota 2009 Characteristics of gas exchange and chlorophyll fluorescence during senescence of flag leaf in different rice (Oryza sativa L.) cultivars grown under nitrogen-deficient condition. Plant Prod. Sci., 12 285-292

Murata, Y. and S. Matsushima 1975 Rice. In "Crop Physiology" ed. by L. T. Evans, Cambridge University Press, Cambridge (England), pp. 73-99

Nagata, K., S. Yoshinaga, J. Takahashi. and T. Terao 2001 Effects of dry matter production, translocation of nonstructural carbohydrates and nitrogen application on grain filling in rice cultivar Takanari, a cultivar bearing a large number of spikelets. Plant Prod. Sci., 4: 173-183

Ortiz-Monasterio, R. J. I., K. D. Sayre, S. Rajaran, and M. McMahon 1997 Genetic progress in wheat yield and nitrogen use efficiency under four nitrogen rates. Crop Sci., 37: 898-904

Takeda, T., M. Oka and W. Agata 1989 Characteristics of dry matter and grain production of rice cultivars in the warmer part of Japan. II. Comparison of grain production between old and new types of rice cultivars. Jpn. J. Crop. Sci., 53: 12-21

Yoshida, S. 1981 Physiological analysis of rice yield. In "Fundamentals of Rice Crop Science" ed. by S. Yoshida, International Rice Research Institute, Manila (Philippines). pp. 30-45

Yoshida, S. and F. T. Parao 1976 Climatic influence on yield and yield components of lowland rice in the tropics. In "Climate and Rice" eds. by S. Yoshida and F. T. Parao, International Rice Research Institute, Manila (Philippines), pp. 471-494 